\title{
A differently managed Spleen Injury
}

\author{
${ }^{1} \mathrm{G}$ Shoor, ${ }^{2} \mathrm{SK}$ Rulaniya, ${ }^{3} \mathrm{KA}$ Mukherjee, ${ }^{4} \mathrm{H}$ Sengupta, ${ }^{5} \mathrm{AK}$ Saraf
}

\begin{abstract}
Introduction: Treatment of symptomatic splenic injury after more than 1 month of the trauma is not very specific. Moreover, here, we are reporting such a case where the patient was treated laparoscopically salvaging the spleen.
\end{abstract}

Case report: A 26-year-old young male presented with persistent pain in the left upper abdomen and back, following a splenic injury while playing football 1 month ago. Abdominal ultrasound showed subcapsular hematoma with intact hilum. Contrastenhanced computed tomography of whole abdomen showed large subcapsular hematoma grade III with intact hilar vessels. In view of persistent pain and discomfort, which debilitated and restrained him from daily as well as professional activity, even after 1 month of trauma, the patient was planned for diagnostic laparoscopy and proceed, which revealed hemoperitoneum and was aspirated. Omentum was separated from splenic capsule, breech in the capsule was extended, and hematoma was sucked out. The drain was removed on 4th postoperative day after ultrasound to exclude any fresh hemorrhage. The patient soon started daily activity and resumed his job after 15 days.

Conclusion: Surgical intervention in a hemodynamically stable splenic-injury patient may sometimes be required depending upon the condition and symptoms of the patient.

Keywords: Diagnostic laproscopy, Spleen injury, Trauma.

How to cite this article: Shoor G, Rulaniya SK, Mukherjee KA, Sengupta H, Saraf AK. A differently managed Spleen Injury. Int J Recent Surg Med Sci 2016;2(1):49-51.

\section{Source of support: Nil}

Conflict of interest: None

\section{CASE REPORT}

A 26-year-old young male presented with the chief complaint of pain in the left upper abdomen and back, which had begun after a fall on back while playing football 1 month ago. The pain was persistent, dull in character, not related to food intake, and not relieved by oral medications. The patient did not give any history suggestive of head injury or hemodynamic instability following

\footnotetext{
${ }^{1,2}$ Postgraduate Student, ${ }^{3}$ Assistant Professor, ${ }^{4}$ Professor and Head, ${ }^{5}$ Professor and Principal

${ }^{1-5}$ Department of General Surgery, Ramakrishna Mission Seva Pratishthan, Vivekananda Institute of Medical Sciences, Kolkata West Bengal, India

Corresponding Author: SK Rulaniya, Postgraduate Student Department of General Surgery, Ramakrishna Mission Seva Pratishthan, Vivekananda Institute of Medical Sciences, Kolkata West Bengal, India, Phone: +918450019194, e-mail: talk2 surgeon@gmail.com
}

the above trauma. Clinical examination revealed a mild tender palpable lump in the left hypochondrium, which moved with respiration without any sign of external injury.

Ultrasound abdomen was performed outside which showed spleen subcapsular anechoic lesion with internal echoes measuring $13 \times 9 \times 9 \mathrm{~cm}$, likely subcapsular hematoma. Spleen size was $10.2 \mathrm{~cm}$ length with intact hilum.

Contrast-enhanced computed tomography of whole abdomen showed large subcapsular hematoma grade III with intact hilar vessels and no perisplenic collection, i.e, with intact spleen capsule (Figs 1 and 2).

In view of persistent pain and discomfort along with existing large splenic hematoma which debilitated the patient and restrained him from daily as well as

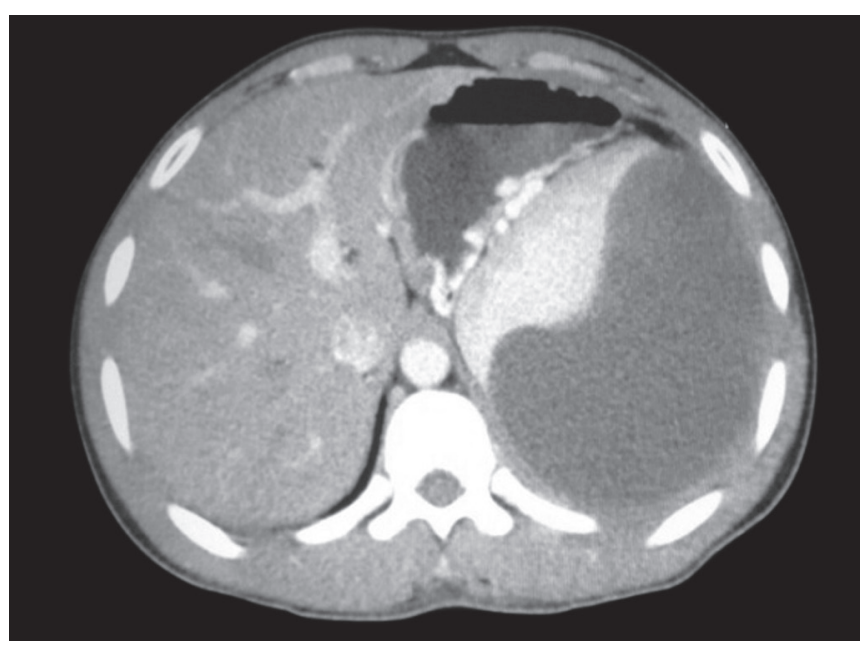

Fig. 1: Contrast-enhanced computed tomography cross-section

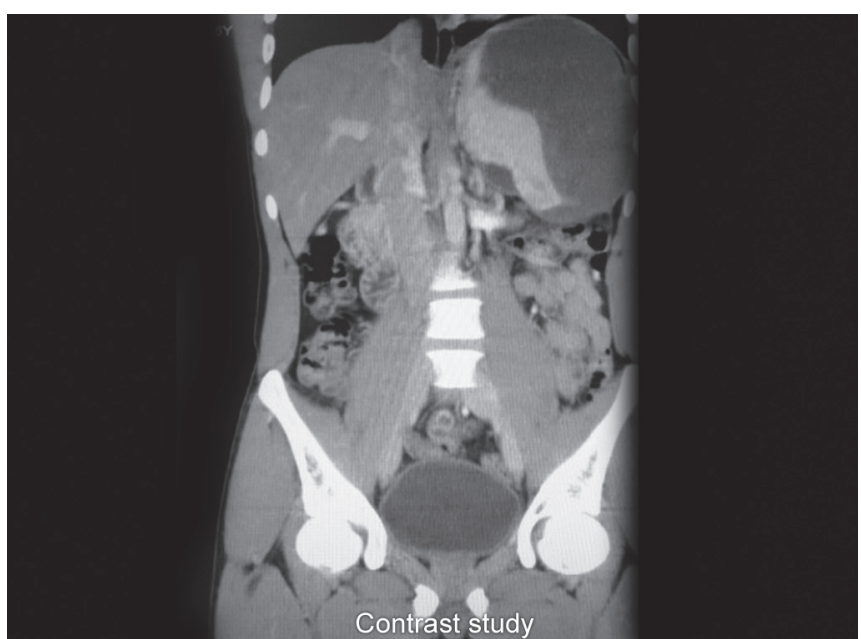

Fig. 2: Contrast-enhanced computed tomography coronal-section 


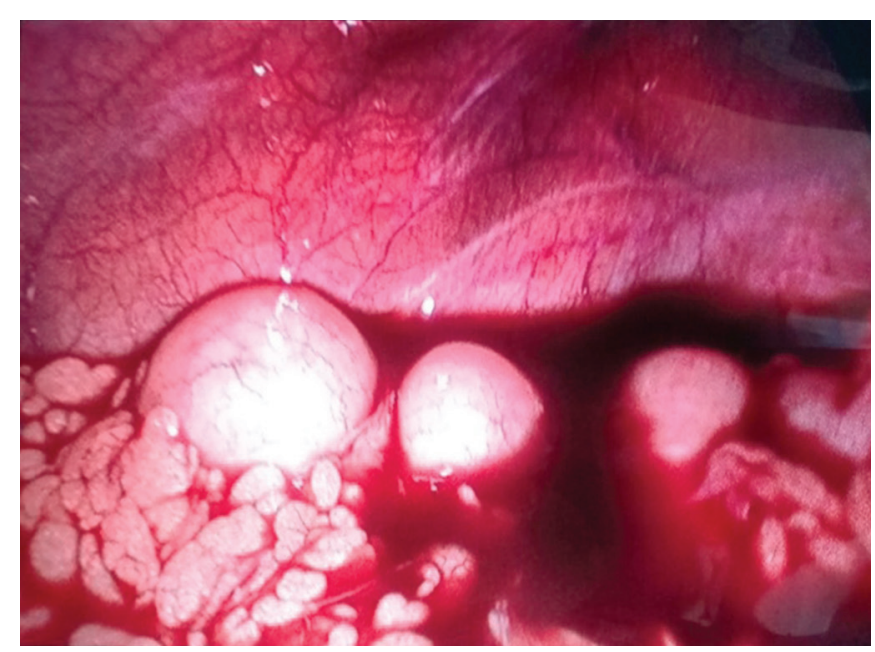

Fig. 3: Old hemoperitoneum

professional activities, even after 1 month of trauma, we had planned for diagnostic laparoscopy and proceed.

\section{PROCEDURE DONE}

Diagnostic laparoscopy was performed through umbilical port, which showed a large intracapsular splenic collection and hemoperitoneum (old altered blood in peritoneal cavity) (Fig. 3). Two $5 \mathrm{~mm}$ working ports were inserted along the right anterior axillary line - one $3 \mathrm{~cm}$ above ASIS and the other $2 \mathrm{~cm}$ below coastal margin. Retained blood was aspirated. Omentum was separated from splenic capsule using ultrasonic device. Breech in the capsule extended using the same, and contents of hematoma sucked out. Deroofing of splenic capsule was done (Fig. 4). Splenic cavity was thoroughly irrigated with normal saline, and any active bleeding was excluded. A drain was placed and ports were taken out.

\section{POSTOPERATIVE PERIOD}

The patient showed improvement from pain and discomfort from postoperative day 2. Drain-contained serosanguinous fluid progressively decreased over 3 days and became serous in nature. The drain was clamped for 24 hours on the 4 th postoperative day before a check ultrasound was done to look for collections. Ultrasound did not show any hematoma, following which the abdominal drain was removed on the 6 th postoperative day. The patient was discharged in stable condition with advice to avoid strenuous activity for 1 month.

\section{FOLLOW-UP}

Patient followed up in OPD 1 week and 15 days after discharge from the hospital, with no fresh complaints, relieved pain, resumed normal daily activity, and declared fit to join duty with advice to avoid athletic activities for another 2 months.

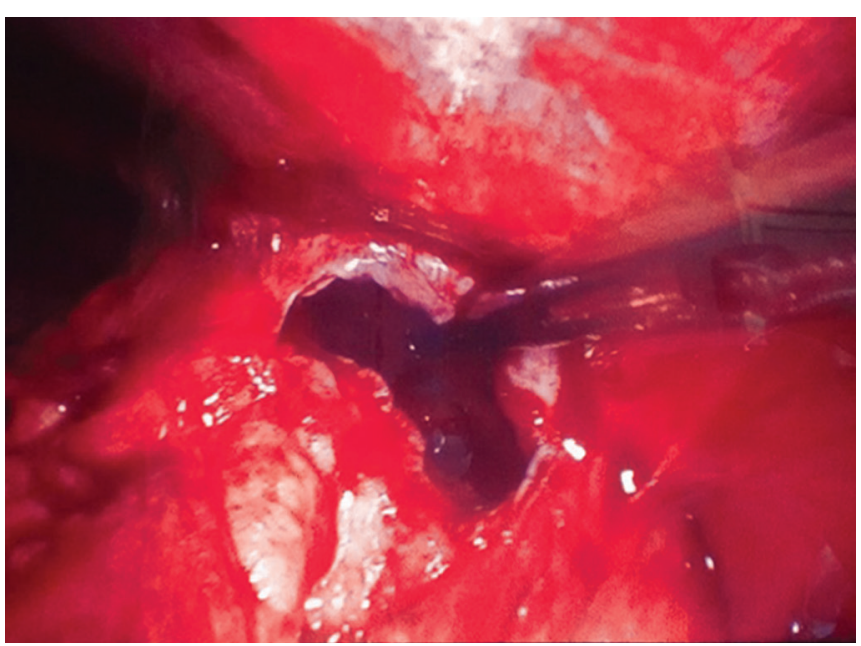

Fig. 4: Subcapsular hematoma aspirated

\section{DISCUSSION}

Blunt Torso trauma is very often associated with different degree of injury to spleen, from subcapsular hematoma to spleen rupture. ${ }^{1}$

The spleen is a shoe-shaped organ located in the left hypochondrium and partly in the epigastrium. It is suspended in the abdominal cavity by ligaments - gastro splenic ligament, splenorenal ligament, and phrenicocolic ligament - but not protected directly by any skeletal structure. As a result, it is very vulnerable to injuries from compression (a direct blow), shock wave (from blast injuries), and deceleration injuries, like those from falls or automobile accidents. Its close association with the lower left ribs makes it prone to injury in polytrauma, associated with fractures of these ribs rather than serving a protective function. ${ }^{2}$

Indications of intervention in splenic trauma: ${ }^{3}$

- Patients with signs of ongoing bleeding or hemodynamic instability, focused assessment with sonography for trauma (FAST) positive.

- Laparotomy is indicated in patients with other intraabdominal organ injury requiring laparotomy.

- Radiological findings, which correlate with need of intervention in hemodynamically stable:

- Devascularization or laceration involving $50 \%$ or more of the spleen parenchyma.

- Contrast blush greater than $1 \mathrm{~cm}$ in diameter (from active extravasation of IV contrast or pseudoaneurysm formation).

- Persistent symptoms restraining from routine and professional activity in hemodynamically stable.

Minimally invasive techniques, such as laparoscopy can be considered when a primarily intra-abdominal injury is suspected in a hemodynamically stable patient. Hemodynamic stability, sufficient to consider laparoscopy in the trauma patient, was defined by Choi and $\mathrm{Lim}^{4}$ as a systolic blood pressure $>100 \mathrm{~mm} \mathrm{Hg}$ and 
diastolic $>60 \mathrm{~mm} \mathrm{Hg}$, a heart rate $<110$ beats per minute, and crystalloid resuscitation requirements of $<2 \mathrm{~L}$.

Laparoscopic examination can also reliably rule out a significant intra-abdominal injury in patients with equivocal abdominal examination, following blunt or penetrating trauma. Diagnostic laparoscopy for trauma has been shown to be effective in preventing negative laparotomy in 21 to $59 \%$ of patients, ${ }^{5-8}$ which can be associated with significant morbidity. ${ }^{9,10}$

The spleen is a major lymphopoietic organ, comprising approximately $25 \%$ of the total lymphoid mass of the body. Normal spleen function is important for opsonization of encapsulated organisms. ${ }^{2}$ Thus, with increasing recognition of the spleen's role in immunological function and awareness of overwhelming postsplenectomy sepsis (OPSI), there has been an increasing trend toward conservative treatment and splenic salvage procedures. ${ }^{11}$

In our patient, a grade III subcapsular spleen hematoma of dimensions $13 \times 9 \times 9 \mathrm{~cm}$ and persistent discomfort was less likely to resolve by its own for a long period. A splenic salvage procedure was performed by means of minimal intervention or laparoscopy, allowing him to get rid of his pain in 2 days, return to daily activity in 2 weeks, avoiding the morbidity associated with laparotomy, and risking OPSI associated with splenectomy.

However, for an unpredictable intervention of the above type, education of the patient and his relatives, explaining the possibility of splenectomy and a proper informed consent, is a must before we proceed.

\section{CONCLUSION}

Although intervention in hemodynamically stable patients with spleen injury after 1 month is not a common practice, the patient's condition necessitates thinking out of the box.

\section{REFERENCES}

1. Mark B, Porter R, Jones T. The Merck manual of diagnosis and therapy. 18th ed. Rahway (NJ): Merck Research Laboratories; 2006.

2. Snell RS. The abdomen: part II. The abdominal cavity. In: Clinical anatomy by regions. 8th ed. Baltimore (MD): Lippincott, Williams \& Wilkins; 2007. p. 259-260.

3. Frumiento C, Vane DW. Changing patterns of treatment for blunt splenic injuries: an 11-year experience in a rural state. J Pediatr Surg 2000 Jun;35(6):985-989.

4. Choi YB, Lim KS. Therapeutic laparoscopy for abdominal trauma. Surg Endosc 2003 Mar;17(3):421-427.

5. Mallat AF, Mancini ML, Daley BJ, Enderson BL. The role of laparoscopy in trauma: a ten-year review of diagnosis and therapeutics. Am Surg 2008 Dec;74(12):1166-1170.

6. Zantut LF, Ivatury RR, Smith RS, Kawahara NT, Porter JM, Fry WR, Poggetti R, Birolini D, Organ CH Jr. Diagnostic and therapeutic laparoscopy for penetrating abdominal trauma-a multicenter experience. J Trauma 1997 May;42(5):825-829.

7. Reiff DA, McGwin G Jr, Metzger J, Windham ST, Doss M, Rue LW 3rd. Identifying injuries and motor vehicle collision characteristics that together are suggestive of diaphragmatic rupture. J Trauma 2002 Dec;53(6):1139-1144.

8. Mazuski JE, Shapiro MJ, Kaminski DL. Diagnostic laparoscopy for evaluation of penetrating abdominal trauma [abstract]. J Trauma 1997;42:163.

9. Ross SE, Dragon GM, O'Malley KF, Rehm CG. Morbidity of negative celiotomy in trauma. Injury 1995 Jul;26(6):393-394.

10. Renz BM, Feliciano DV. The length of hospital stay after an unnecessary laparotomy for trauma: a prospective study. J Trauma 1996 Feb;40(2):187-190.

11. Merchea A, Dozois EJ, Wang JK, Larson DW. Anatomic mechanisms for splenic injury during colorectal surgery. Clin Anat 2012 Mar;25(2):212-217. 